\title{
Quantitation of Urinary Gonadotropins in Normal Children
}

\author{
HATAE MAESAKA, SEIZO SUWA, KATSUHIKO TACHIBANA, AND NOBUYUKI KIKUCHI \\ Department of Pediatrics, Kanagawa Children's Medical Center, Mutsukawa 2-chome, Minami-ku, Yokohama
} 232, Japan

\begin{abstract}
A simple and improved method for the quantification of urinary LH and FSH was developed. Urinary gonadotropin concentrations were determined by polyclonal double antibody RIA after ammonium sulfate extraction. Urinary LH and FSH concentrated by ammonium sulfate were coeluted with an iodinated LH and FSH tracer. Gel chromatography of the urine revealed that the majority of immunoreactive LH and FSH were eluted coincident with ${ }^{125} \mathrm{I}-\mathrm{LH}$ and ${ }^{125} \mathrm{I}-\mathrm{FSH}$. Good correlation was observed between urinary gonadotropin/creatinine ratios in first morning voided and full 24-h urine collections. Age-dependent changes in urinary $\mathrm{LH}$ excretion were significant in normal boys and girls 6-17 y of age. Urinary FSH excretion in these children did not change in an agedependent fashion. (Pediatr Res 28: 401-404, 1990)
\end{abstract}

\section{Abbreviations}

FMV, first morning voided

The initial endocrinologic event of puberty is an increase in the amplitude of pulsatile pituitary LH secretion at night secondary to an increase in hypothalamic pulsatile secretion of gonadotropin-releasing hormone (1). However, pulsatile LH secretion has started in prepubertal children $(2,3)$, but frequent or continuous blood samplings, during the night or over a 24-h period, are necessary to investigate the patterns of pulsatile gonadotropin secretion. This cannot be done easily, especially in normal children. Urinary gonadotropins are thought to reflect the integrated plasma values during the time of collection. It has been reported that FMV urine specimens provide a satisfactory alternative to either serial serum or 24-h urine specimens in children and adult women for studies requiring serial gonadotropin measurements (4-7).

Our purpose was to investigate age-related changes in gonadotropin excretion in normal children. Because FMV urine specimens are easily collected from normal school children at home, we could measure gonadotropins in amounts of urine smaller than those previously reported (8).

\section{SUBIECTS}

FMV urine specimens were collected from 480 normal subjects (240 males and 240 females). The subjects were healthy school

Received October 25, 1989; accepted May 21, 1990.

Reprint requests: Hatae Maesaka, M.D., Department of Pediatrics, Kanagawa Children's Medical Center, Mutsukawa 2-chome, 138-4 Minami-ku, Yokohama 232, Japan.

Supported by a research grant for "Specific Disease" of the Japanese Ministry of Health and Welfare and by a comprehensive research grant regarding prevention of mental and physical disorders awarded by the Japanese Ministry of Health and Welfare. children 6-17 y of age whose urine specimens were collected for mass screening of renal disorders. The urine specimens with no proteinuria were kindly supplied by the Kanagawa Health Service Association.

FMV and 24-h urine collections were obtained from patients 6-13 y of age whose urine specimens contained no proteinuria during hospitalization in Kanagawa Children's Medical Center. FMV urine specimens were obtained from three healthy children aged $8-13$ y and two healthy female adults aged $27-35 \mathrm{y}$. They were all hospital staff members and their families.

\section{MATERIALS AND METHODS}

Urine specimen preparation. Before introduction into the RIA, urinary gonadotropins were extracted with ammonium sulfate. All the urine samples, to which 0.005 vol of $6 \%$ sodium azide had been added, were stored at $4^{\circ} \mathrm{C}$ up to 3 mo until assayed. Four $\mathrm{mL}$ of the urine samples were supplemented with $20 \mu \mathrm{L}$ each of $0.6 \%$ BSA and glacial acetic acid, vortex-mixed, and centrifuged at $3000 \mathrm{rpm}$ for $5 \mathrm{~min}$. To $1 \mathrm{~mL}$ of the urine supernatant, $0.5 \mathrm{~g}$ of powdered ammonium sulfate was added to achieve approximately $75 \%$ saturation. The tubes were vortexmixed, allowed to stand for $30 \mathrm{~min}$ at room temperature, and centrifuged at $3000 \mathrm{rpm}$ for $30 \mathrm{~min}$. After aspiration of the supernatant, the pellets were dissolved and neutralized with 100 $\mu \mathrm{L}$ of $0.05 \mathrm{M}$ veronal buffer solution, $\mathrm{pH}$ 8.6. Otherwise, extraction procedures were the same as previously reported (9). The urine was concentrated 10 -fold for the prepubertal children and 5 -fold for the pubertal children.

Immunoassay. Routine measurements of $\mathrm{LH}$ and FSH in urine after ammonium sulfate extraction were made by a polyclonal double antibody RIA kit obtained from Eiken Co., Tokyo, Japan. The assay procedure described by the manufacturer was used. LH standard was calibrated WHO 1st IRP 68/40 and FSH standard against the 2 nd IRP of pituitary $78 / 549$.

To study the gel chromatographic patterns of immunoreactive LH and FSH in urine, $1 \mathrm{mg}$ of BSA (Armour Pharmaceutical Co., Kankakee, IL) was added to $20 \mathrm{~mL}$ of urine from a normal female adult and extracted with ammonium sulfate. The concentrated urine (final volume $1.0 \mathrm{~mL}$ ) was applied on a $0.95 \times 45$ cm Sephadex G-100 (Pharmacia Fine Chemicals, Uppsala, Sweden) column and eluted with $0.05 \mathrm{M}$ veronal buffer solution $\mathrm{pH}$ 8.6 containing $0.5 \%$ BSA. Each fraction was assayed by RIA for $\mathrm{LH}$ and FSH. All specimens from a single subject were assayed in the same RIA. To minimize possible error in urine collections and wide variation in body size, immunoreactive LH and FSH in urine were expressed as $\mathrm{IU} / \mathrm{g}$ urinary creatinine (IU/g Cr). Creatinine concentration in urine was measured by the Jaffe reaction using an autoanalyzer. Differences among mean $\mathrm{LH}$ and FSH concentrations of the study groups were detected by analysis of variance using Duncan's multiple range test. Statistical significance for sex differences was determined by the unpaired $t$ test. Values are expressed as mean and SD. 

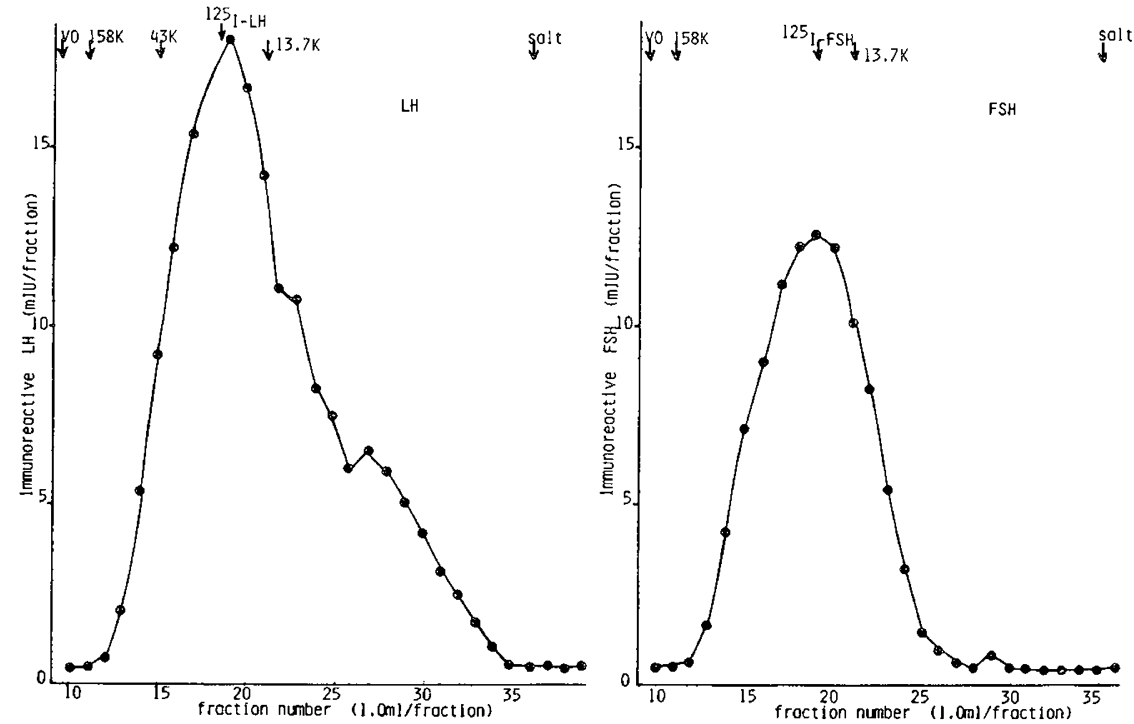

Fig. 1. Gel filtration profiles of immunoreactive LH and FSH in urine from a normal female adult. Twenty mL of the urine sample was concentrated, applied to a $0.95 \times 45 \mathrm{~cm}$ Sephadex G-100 column, and eluted with $0.05 \mathrm{M}$ veronal buffer solution containing $0.5 \% \mathrm{BSA}$, pH 8.6 . Each fraction was assayed by RIA for LH and FSH. Calibration was made with blue dextran $(V O)$, aldolase (158K), ovalbumin (43K), ribonuclease $\mathrm{A}(13.7 \mathrm{~K}),{ }^{125} \mathrm{I}-\mathrm{FSH},{ }^{125} \mathrm{I}-\mathrm{LH}$, and ${ }^{125} \mathrm{I}-\mathrm{Na}($ salt $)$.
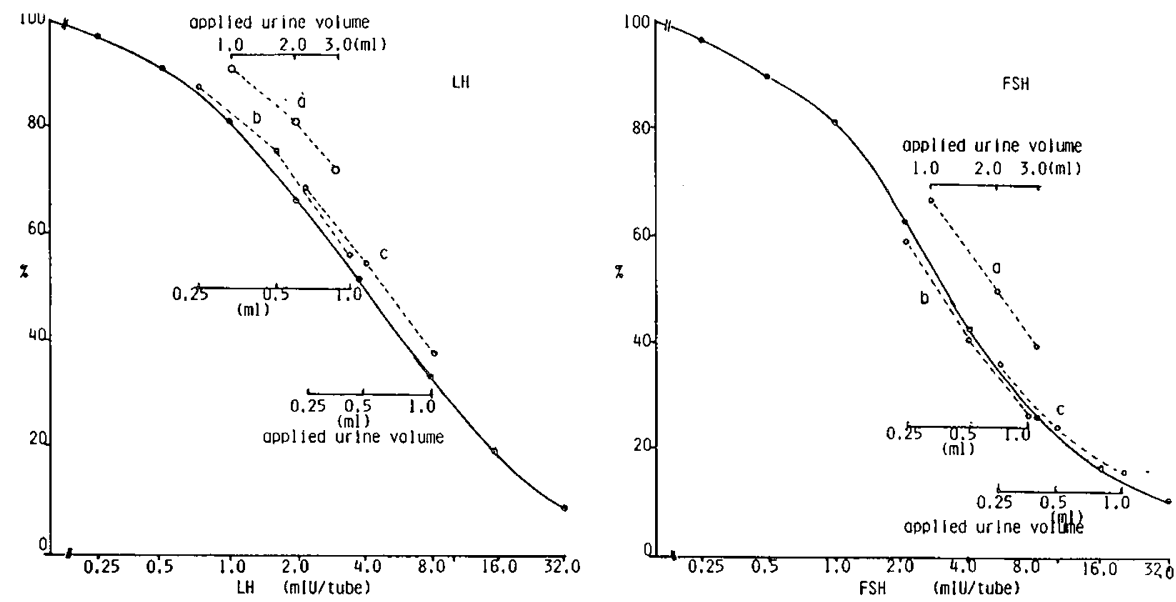

Fig. 2. Standard curve for urinary LH and FSH RIA. Urine samples from three normal children, all family members of the hospital staff, were used for this study. $a$, boy aged $8 \mathrm{y} ; b$, girl aged $9 \mathrm{y}, c$, girl aged $13 \mathrm{y}$.
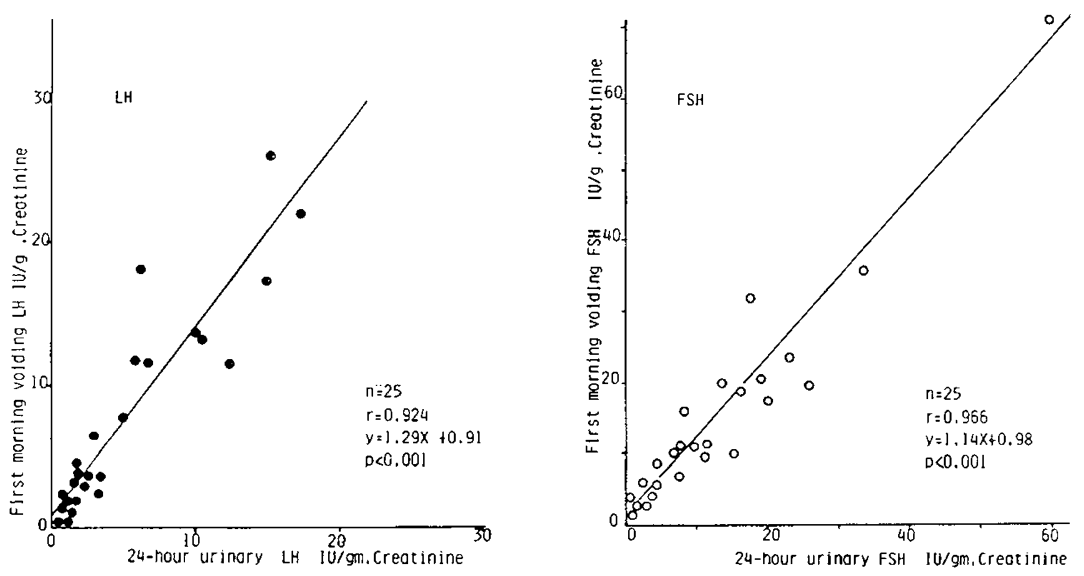

Fig. 3. Correlation between $\mathrm{LH}$ and FSH values from FMV and 24-h urine specimens collected from 25 children. 
Urinary $L H$ and FSH. The gel chromatographic patterns of immunoreactive LH and FSH are shown in Figure 1. Urinary LH and FSH concentrated by ammonium sulfate were coeluted with an iodinated LH and FSH tracer. Most of immunoreactivity was eluted coincident with the radioactive peak of ${ }^{125}$ I-FSH and ${ }^{125} \mathrm{I}-\mathrm{LH}$.

In our RIA system for urinary LH and FSH, the binding of ${ }^{125} \mathrm{I}-\mathrm{LH}$ and ${ }^{125} \mathrm{I}-\mathrm{FSH}$ in the absence of unlabeled hormone was $\sim 40-50 \%$ of total radioactivity applied. The sensitivity of the $\mathrm{LH}$ and FSH RIA system was $0.25 \mathrm{mIU} /$ tube. About $4.5 \mathrm{mIU} /$ tube of unlabeled LH gave $50 \%$ displacement of ${ }^{125} \mathrm{I}-\mathrm{LH}$ binding and $3.5 \mathrm{mIU} /$ tube of unlabeled $\mathrm{FSH}$ gave $50 \%$ displacement of ${ }^{125} \mathrm{I}-\mathrm{FSH}$ binding. The recovery of radiolabeled LH and FSH through the extraction was $99.2 \pm 0.3$ and $98.1 \pm 1.2 \%$, respectively $(n=5$, mean $\pm \mathrm{SD})$. When $4.0 \mathrm{mIU} /$ tube of unlabeled LH and FSH were extracted and measured by RIA, the recovery of immunoreactivity was $97.5 \pm 2.5$ and $95.1 \pm 4.0 \%$, respectively $(n=5$, mean $\pm \mathrm{SD})$. Parallelism between standard and extracted urine is shown in Figure 2. The intraassay coefficient of variation for the LH and FSH RIA system including the extraction process was $\sim 4.5-9.0 \%$. When urine specimens from a girl aged $11 \mathrm{y}$ stored at $4^{\circ} \mathrm{C}$ were measured at 2,4 , and $12 \mathrm{wk}$ of storage, the values of LH were $1.3,1.2$, and $1.4 \mathrm{mIU} / \mathrm{mL}$ and the values of FSH were 13.3, 13.0, and $13.9 \mathrm{mIU} / \mathrm{mL}$. When urine samples from a boy aged 13 y stored at $4^{\circ} \mathrm{C}$ were measured at 4,8 , and $12 \mathrm{wk}$ of storage, the values of $\mathrm{LH}$ were $21.1,20.3$, and $20.9 \mathrm{mIU} / \mathrm{mL}$ and the values of FSH were $16.9,17.8$, and $17.1 \mathrm{mIU} / \mathrm{mL}$. The correlations between urine gonadotropin/ creatinine ratios in FMV and 24-h urine collections are shown in Figure 3. The respective correlation coefficients are 0.92 for $\mathrm{LH}(n=25)$ and 0.97 for FSH $(n=25)$.

Normal values in FMV urinary LH and FSH according to age. Urinary concentrations of $\mathrm{LH}$ and FSH from normal subjects of different ages are shown in Table 1.

The concentrations of urinary LH increased slowly until age $12 \mathrm{y}$, and thereafter increased rapidly in normal boys and girls. Age-dependent changes in urine LH excretion were statistically significant as shown in Table 1. Urinary levels of LH in the girls aged 13-15 y were statistically greater than those for age-matched boys $(p<0.01)$. Urinary FSH excretion increased slightly at the age of $8 \mathrm{y}$, and thereafter did not change in either sex of children.

\section{DISCUSSION}

The gel chromatographic study revealed that the majority of the immunoreactive $\mathrm{LH}$ and FSH were eluted with ${ }^{125} \mathrm{I}-\mathrm{LH}$ and ${ }^{125}$ I-FSH, suggesting that most of the urinary materials are monomeric LH and FSH.

Inasmuch as the concentrations of $\mathrm{LH}$ and FSH in urine were about $1 / 10$ the corresponding plasma level, and the levels of $\mathrm{LH}$ and FSH were low in prepubertal children, the measurement of urinary $\mathrm{LH}$ and $\mathrm{FSH}$ required extraction and concentration before RIA. The acetone extraction method reported by Kulin et al. (5) and Reiter et al. (8) would require a large amount of acetone and urine. Ammonium sulfate precipitation is suitable for polypeptides of high molecular weight. We observed that $67-$ $75 \%$ saturated ammonium sulfate precipitated $\sim 93-97 \%$ of radioactive LH and FSH added to urine. This simple, quick, and inexpensive method of extraction requires a small amount of urine, permits easy extraction of many samples at the same time, consistently provides a high recovery rate, and provides enough sensitivity for $\mathrm{LH}$ and FSH determinations in urine. In addition, this method might denature urinary protein less than would previously reported methods using acetone. The ammonium sulfate extraction study with ionic ${ }^{125}$ I revealed that this step was also effective in removing urinary salts, as reported previously (9). The extraction method involved addition of BSA as well as acetic acid (9). All urine samples were supplemented with BSA 
to prevent the adsorption of urinary $\mathrm{LH}$ and FSH to the tube walls and to achieve a high extraction rate.

Age-dependent changes in urinary LH excretion were statistically significant in normal boys and girls. The levels of FMV urinary LH and FSH excretion in these boys were comparable with the findings for 24-h urinary excretion of LH and FSH in normal male children reported by Baghdassarian et al. (10). Agedependent changes in urinary $\mathrm{LH}$ and FSH excretion in these normal boys and girls were comparable with the findings in the levels of serum LH and FSH in normal children of different ages $(11,12)$. This method for quantitation of urinary LH and FSH may play an important role in studying the physiology of normal and abnormal puberty.

Acknowledgments. The authors thank S. Igarashi, Director of Kanagawa Health Service Association, and the healthy volunteers who provided normal urine specimens. We thank Dr. A. Ogiwara, Yokohama City University School of Medicine, for the helpful advice on statistical analysis. The authors thank Y. Ogawa, Kanagawa Children's Medical Center, for the measurement of urine creatinine.

\section{REFERENCES}

1. Boyar R, Finkelstein J, Roffwarg H, Kapen S, Weitzman E, Hellman L 1972 Synchronization of augmented luteinizing hormone secretion with sleep during puberty. N Engl J Med 287:582-586

2. Jakacki RI, Kelch RP, Sauder SE, Lloyd JS, Hopwood NJ, Marshall JC 1982
Pulsatile secretion of luteinizing hormone in children. $\mathbf{J}$ Clin Endocrinol Metab 55:453-458

3. Corley KP, Valk TW, Kelch RP, Marshall JC 1981 Estimation of GnRH pulse amplitude during pubertal development. Pediatr Res 15:157-162

4. Hansen JW, Ross GT 1975 A new method simplifying collection of serial specimens for gonadotropin determinations. J Clin Endocrinol Metab 41:241-244

5. Kulin HE, Bell PM, Santen RJ, Ferber AJ 1975 Integration of pulsatile gonadotropin secretion by timed urinary measurements. An accurate and sensitive 3-hour test. J Clin Endocrinol Metab 40:783-789

6. Beitins IZ, O'Loughlin K, Ostrea T, McArthur JW 1976 Gonadotropin determinations in timed 3-hour urine collections during the menstrual cycle and LHRH testing. J Clin Endocrinol Metab 43:46-55

7. Chipman JJ, Moore RJ, Marks JF, Fevre M, Segel T, Ramsey J, Boyar RM 1981 Interrelationship of plasma and urinary gonadotropins: correlations for 24 hours for sleep/wake periods, and for 3 hours after luteinizing hormonereleasing hormone stimulation. J Clin Endocrinol Metab 52:225-230

8. Reiter EO, Kulin HE, Hamwood SM 1973 Preparation of urine containing small amounts of FSH and LH for radioimmunoassay: comparison of the kaolin-acetone and acetone extraction techniques. J Clin Endocrinol Metab $36: 661-666$

9. Yokoya S, Suwa S, Maesaka H, Tanaka T 1988 Immunoreactive somatomedin $\mathrm{C} /$ insulin-like growth factor-1 in the urine from normal subjects, pituitary dwarfs and acromegalies. Pediatr Res 23:151-154

10. Baghdassarian A, Guyda H, Johanson A, Migeon CJ, Blizzard RM 1970 Urinary excretion of radioimmunoassayable luteinizing hormone (LH) in normal male children and adults, according to age and stage of sexual development. J Clin Endocrinol Metab 31:428-435

11. August GP, Grumbach MM, Kaplan SL 1972 Hormonal changes in puberty: III. Correlation of plasma testosterone, LH, FSH, testicular size and bone age with male pubertal development. J Clin Endocrinol Metab 34:319-326

12. Jenner MR, Kelch RP, Kaplan SL, Grumbach MM 1972 Hormonal changes in puberty: IV. Plasma estradiol, LH and FSH in prepubertal children, pubertal females and in precocious puberty, premature thelarche, hypogonadism, and in a child with a feminizing ovarian tumor. J Clin Endocrinol Metab 34:521-529

\section{Announcement}

\section{Joint PhD-Fellowship Training Program}

The University of Chicago Department of Pediatrics announces its unique, new Pediatric Science Training/ $\mathrm{PhD}$ Program. Trainees wishing to pursue an academic career may simultaneously pursue subspecialty training and a graduate school program leading to the $\mathrm{PhD}$ degree in the 5-year program. Training is available in most pediatric subspecialties, and research opportunities are available in diverse fields, including the social and behavioral sciences as well as the biologic sciences. Applications are being accepted for 1991. This program is funded by the National Institutes of Child Health and Human Development. Consequently, the program is only open to U.S. citizens or permanent residents. Address inquiries to: Robert L. Rosenfield, M.D., Program Director, Pediatric Science Training/PhD Program, Wyler Children's Hospital, 5841 South Maryland, Chicago, IL 60637. 